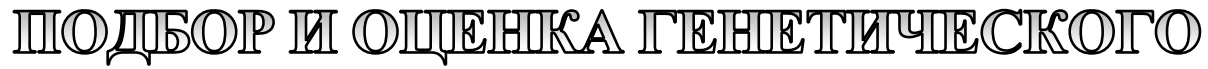

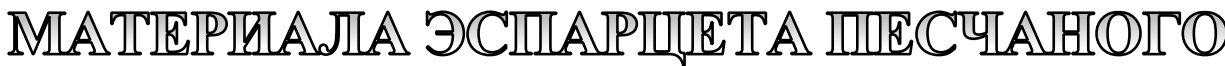

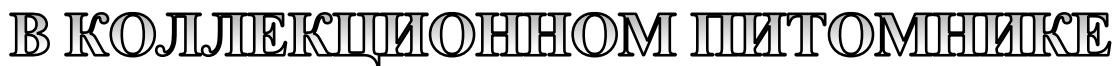

\section{В.А. Волошин, Пермский научно-исследовательский институт сельского хозяйства}

Приведены результаты исследований на травостоях эспарцета песчаного (Onobrichis arenaria (Kit) DC первого года жизни и первого года пользования, полученные в двух последовательных во времени закладках. Объекты исследований - селекционные сорта СибНИИК-30, Петушок, Песчаный 22 и образцы из дикой фрлоры Д-1, Д-2, Д-3. Способы посева сортообразцов рядовой, образцов-дикоросов ввиду дефицита семян-черезрядный беспокровный. Норма высева сортов 400, дикоросов - 200 всхожих семян на $1 \mathrm{~m}^{2}$. Представлены данные по густоте всходов, полевой всхожести, перезимовке растений, урожайности зеленой массы и семян. При летнем посеве в 2016 году, в условиях дефицита почвенной влаги, селекционные сортообразцы развивались по озимому типу, сформировав к осени розетки из 5 и более укороченных побегов. При весеннем посеве, благоприятной влажности почвы в 2017 году высота молодых растений достигла 76-96 см, наблюдались отдельные цветущие побеги, то есть развитие шло по яровому типу. Образцы - дикоросы, независимо от погодных условий и сроков посева, развивались по озимому типу, фрормируя 3,3-4,4 и 4,0-5,0 укороченных побегов на растение в 2016 и 2017 годах соответственно. В первой закладке в первую зиму хорошо сохранились растения сорта СибНИИК-30, у остальных образцов погибло 40-50\% от осеннего количества растений. Во второй закладке отлично перезимовали образцы - дикоросы, у селекционных посевов погибло более $50 \%$ растений. В среднем по двум закладкам на травостоях первого года пользования биологическая урожайность зеленой массы

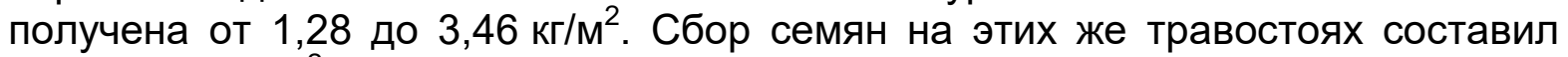
$59,16-92,57 \mathrm{r} / \mathrm{M}^{2}$.

Ключевые слова: эспариет песчаный, селекциионные сорта, образиьь-дикоросы, урожайность зеленой массы, урожайность семян.

Повышение продуктивности животноводства, его поступательное стабильное развитие неразрывно связаны с организацией сбалансированного кормления скота и ликвидацией дефицита энергии, сырого протеина и других питательных веществ в рационах. Расширение ассортимента кормовых растений, замена малопродуктивных видов и сортов более урожайными и ценными в питательном отношении, то есть совершенствование структуры посевных площадей является значительным резервом для увеличения производства кормов и улучшения их качества $[1,3,5]$. 
Совершенствование структуры посевных площадей кормовых культур, интенсификация кормопроизводства возможны за счет использования уже имеющихся высокопродуктивных видов и сортов кормовых растений, а также за счет интродукции новых видов и сортов кормовых культур, наиболее полно использующих природно-климатические условия региона $[4,7,12,14]$. Несомненный интерес представляют местные виды из дикорастущих популяций [11].

Первые научные работы с исходным материалом в нашей стране датируются 1904 годом, когда В.Р. Вильямс совместно с В.С. Богданом организовали при Петровской CXА коллекционный питомник для изучения луговых кормовых растений. Вовлечение дикорастущих генетических ресурсов в селекционный процесс продолжается и в настоящее время [6].

Создание такой коллекции и выделение доноров хозяйственно-ценных признаков в перспективе позволит в соответствии с задачами селекции целенаправленно подбирать пары для скрещивания, планировать оптимальную численность расщепляющихся популяций, определять количество и порядок проведения отборов, то есть проводить целенаправленную селекционную работу, резко сокращать затраты времени, материальных средств и финансов на создание нового или уже районированного сорта. При этом следует согласиться с мнением А.А. Тореханова [13], что генофонд растений является таким же национальным богатством нашей страны, как нефть, газ, уголь и другие ресурсы.

Традиционные многолетние бобовые травы, такие как клевер луговой, люцерна изменчивая, козлятник восточный, лядвенец рогатый, и их смеси со злаковыми травами занимают в Пермском крае более половины площадей кормовых культур на пашне. Тем не менее, расширение ассортимента видов и сортов трав является наиболее действенным и экономически оп- равданным направлением хозяйственной деятельности. Одной из перспективных культур для Пермского края может быть эспарцет песчаный, который в местных условиях до настоящего времени не возделывался, но встречается в естественной флоре в Ординском, Суксунском и Кунгурском районах.

Эспарцет песчаный Onobrichis arenaria (kit) - многолетнее травянистое растение семейства бобовых (Fabaceae). Культура скороспелая, при достаточном увлажнении формирует 2 укоса за сезон. По кормовым достоинствам не уступает клеверу и люцерне, хороший медонос. Корневая система эспарцета способна использовать труднорастворимые соединения кальция и фосфора из почвы. По мнению В.В. Люшинского и Ф.Б. Прижукова [8], к достоинствам эспарцета следует отнести самую высокую и наиболее устойчивую по сравнению с другими видами многолетних бобовых трав семенную продуктивность.

Цель исследований - провести оценку коллекции селекционных сортов и образцов, полученных из семян, собранных в естественной флоре.

Задачи исследований:

1. Установить особенности роста образцов коллекции в первый год жизни.

2. Сравнить урожайность зеленой массы и семян образцов в первый год пользования.

3. Выявить хозяйственно-ценные признаки, представляющие интерес для сельскохозяйственного производства и селекции в перспективе.

\section{Объект и методы исследований}

Питомник по интродукции кормовых культур заложен в 2016 году на опытном поле Пермского НИИСХ. За основу выполнения исследований взяты «Методические указания по изучению коллекции многолетних кормовых трав [9], «Методика полевого опыта» [2] и «Методика опытов на 
сенокосах и пастбищах» [10]. Объект исследований - селекционные сорта эспарцета песчаного СибНИИК-30 (Новосибирск, НИИ кормов), Петушок (Пензенский НИИСХ), Песчаный 22 (Башкирский НИИСХ) и три образца из семян, собранных в дикой флоре Ординского и Суксунского районов. Способ посева сортообразцов рядовой, образцов-дикоросов ввиду дефицита семян - черезрядный беспокровный. Норма высева сортов - 400, дикоросов - 200 штук всхожих семян на $1 \mathrm{~m}^{2}$.

\section{Результаты исследований}

Начиная изучать новый для региона вид, важно установить особенности формирования его травостоя в местных условиях в год посева, а также выявить роль среды, в частности погодных условий, определяющих все этапы роста и развития молодых растений.

В 2016 году в условиях высоких среднесуточных температур воздуха мая, отсутствия осадков и иссушения почвы посев эспарцета провели 10 июня после небольших дождей. Начало всходов у сортов отмечено на 20-25-й день от посева, а полные всходы сформировались в последующие 15-18 дней. Всходы из семян, собранных в дикой флоре, начали появляться на 33-34-е сутки, и этот период длился 7-14 дней.

Установившаяся в дальнейшем жаркая, без дождей погода обусловила вплоть до сентября острый дефицит почвенной влаги, что отрицательно сказалось на росте и развитии растений. К середине июля $\mathrm{y}$ сортов на $1 \mathrm{~m}^{2}$ сформировалось от 180 до 236 растений, полевая всхожесть была не- высокой - 45-59\%. У образцов - дикоросов количество всходов было меньше 12-144 шт./м², разброс значений был более широкий - 6-72\% (табл. 1).

На этом этапе изучения коллекции необходимо отметить различия в форме розетки: у «дикоросов» она стелющаяся, а у селекционных образцов - более компактная, эректоидная. До конца вегетации все образцы оставались в фазе розетки из укороченных побегов. У контрольного образца СибНИИК-30 их было 5,4; Д-1 - 4,1; Д-2 - 3,3; Д-3 - 4,4 штуки на растение. Таким образом, при летнем посеве, в условиях повышенной температуры воздуха, сокращающемся световом дне и дефиците почвенной влаги в течение вегетации эспарцет песчаный в первый год жизни развивается по озимому типу.

В более прохладном и влажном по сравнению с 2016 годом мае 2017 года посев коллекции провели 18-го числа. Лето в целом можно охарактеризовать как достаточно влажное, в отдельные периоды - избыточно увлажненное, прохладное. В сумме за период май-сентябрь недобор положительных температур по сравнению с 2016 годом составил более $600^{\circ} \mathrm{C}$. В этих условиях сорта начали всходить на 12-15-й день от посева, «дикоросы» - на 27-30-й день. Формирование полных всходов у сортообразцов продолжалось 3-7 дней, у «дикоросов» этот период растянулся практически на месяц. К концу июня у сортов на $1 \mathrm{~m}^{2}$ сформировалось 276-304 растения, полевая всхожесть была в пределах 69-76\%, это выше, чем в 2016 году. У образцов

Таблицุа 1

Густота всходов и полевая всхожесть эспарцета песчаного

\begin{tabular}{|c|c|c|c|c|c|c|}
\hline \multirow{2}{*}{ Образец } & \multicolumn{2}{|c|}{$\begin{array}{c}\text { Высеяно } \\
\text { семян, шт./м² }\end{array}$} & \multicolumn{2}{c|}{$\begin{array}{c}\text { Взошло } \\
\text { растений, шт./м² }\end{array}$} & \multicolumn{2}{|c|}{$\begin{array}{c}\text { Полевая } \\
\text { всхожесть,\% }\end{array}$} \\
\cline { 2 - 8 } & $\mathbf{2 0 1 6}$ г. & $\mathbf{2 0 1 7}$ г. & $\mathbf{2 0 1 6}$ г. & $\mathbf{2 0 1 7}$ г. & $\mathbf{2 0 1 6}$ г. & $\mathbf{2 0 1 7}$ г. \\
\hline Сорт СибНИИК-30 & 400 & 400 & 236 & 304 & 59 & 76 \\
\hline Сорт Петушок & 400 & 400 & 224 & 292 & 56 & 73 \\
\hline Сорт Песчаный 22 & 400 & 400 & 180 & 276 & 45 & 69 \\
\hline Дикорос 1 (Д-1) & 200 & 200 & 87 & 160 & 44 & 80 \\
\hline Дикорос 2 (Д-2) & 200 & 200 & 12 & 52 & 6 & 26 \\
\hline Дикорос 3 (Д-3) & 200 & 200 & 144 & 56 & 72 & 28 \\
\hline
\end{tabular}


«дикоросов» при черезрядном посеве было 52-160 шт./м², а полевая всхожесть от 20 до 80\%. При сравнении этих показателей за два рассматриваемых года видно, что для селекционных образцов решающим условием получения полноценных всходов является увлажнение почвы. Для «дикоросов», очевидно, более значимым является качество посевного материала, сформировавшееся в разных погодных условиях (2015 и 2016 годы) в разных географических точках края.

В дальнейшем рост и развитие растений селекционных сортов и из семян, собранных в естественных фитоценозах, сильно отличались. К середине сентября 2017 года у сортовых образцов растения развились до фазы цветения, высота их достигла 76,696,7 см. Дикоросы, как и в 2016 году, к концу вегетации сформировали только розетку из укороченных побегов, которых по образцам было у ДЭ-1 - 4,2; ДЭ-2 - 4,0; ДЭ-3 - 5 шт. на растение.

На закладке 2016 года к весне 2017 года (І г.п.) хорошо сохранился сорт СибНИИК-30, у остальных образцов погибло $40-50 \%$ от осеннего количества растений. Необходимо отметить, что весной 2017 года у образцов «дикоросов» наблюдались всходы из семян, посеянных в 2016 году. Однако процесс этот был растянут во времени, и точно определить количество всходов под покровом быстрорастущих перезимовавших растений было невозможно. В коллекции посева 2017 года к весне 2018 года отлично сохранились образцы «дикоросы». Сортовые посевы погибли более чем на 50\%.
При этом их отрастание было очень недружным, замедленным.

По урожайности зеленой массы в годы наблюдений четкой разницы между образцами не выявлено. На первой закладке сбор корма был выше у сортообразцов, на второй, как было сказано выше, сортообразцы перезимовали неудовлетворительно и укосной массы не дали. Дикоросы же даже в условиях острого дефицита почвенной влаги в 2018 году к концу июня имели высоту растений 74-79 см, сформировав на $1 \mathrm{~m}^{2}$ 0,80-2,28 кг зеленой массы (табл. 2).

Проведенный в 2018 году биохимический анализ кормовой массы показал, что эспарцет песчаный по энергопротеиновой оценке не уступает люцерне и клеверу луговому: в 1 кг сухого вещества этих трав содержалось 11,00 и 9,90, и 9,71 МДж обменной энергии и 19,37, 19,33 и $15,04 \%$ сырого протеина соответственно.

При анализе урожайности семян в среднем за 2 года исследований выявлено, что наибольший их сбор $\left(92,57\right.$ г/м $\left.{ }^{2}\right)$ обеспечил образец Д-1. Такую же среднюю урожайность обеспечил и сорт СибНИИК-30. Как положительное качество этого образца необходимо отметить, что в контрастных погодных условиях 2017 и 2018 годов он формировал одинаковую массу 1000 семян (табл. 3).

Анализируя скорость созревания семян, выявлено, что все семена эспарцета песчаного в травостое созревают за 10-12 дней. Однако быстрее всех восковой спелости (67\% от общего урожая) достигли семена образца Д-3. У остальных образцов созревание семян было более растянутым

Урожайность зеленой массы эспарцета песчаного

\begin{tabular}{|c|c|c|c|c|c|}
\hline \multirow[t]{2}{*}{ Образец } & \multicolumn{2}{|c|}{$\begin{array}{c}\text { Высота } \\
\text { растения, см }\end{array}$} & \multicolumn{3}{|c|}{$\begin{array}{c}\text { Урожайность зеленой } \\
\text { массы, кг/м² }\end{array}$} \\
\hline & 2017 г. & 2018 г. & 2017 г. & 2018 г. & средняя \\
\hline СибНИИК-30 & 118,7 & - & 6,92 & - & 3,46 \\
\hline Петушок & 104,8 & - & 3,52 & - & 1,76 \\
\hline Песчаный 22 & 96,3 & - & 2,56 & - & 1,28 \\
\hline Дикорос 1 & 81,8 & 74,7 & 2,40 & 0,80 & 1,60 \\
\hline Дикорос 2 & 89,7 & 74,0 & 1,28 & 1,28 & 1,28 \\
\hline Дикорос 3 & 82,0 & 77,9 & 1,20 & 2,28 & 1,74 \\
\hline
\end{tabular}




\begin{tabular}{|c|c|c|c|c|c|c|}
\multicolumn{2}{c|}{ Урожайность семян эспарцета песчаного второго года жизни } \\
\hline \multirow{2}{*}{ образец } & \multicolumn{3}{|c|}{ Урожайность, г/м² } & \multicolumn{3}{|c|}{ Масса 1000 шт., г } \\
\cline { 2 - 7 } & $\mathbf{2 0 1 7}$ г. & $\mathbf{2 0 1 8}$ г. & средняя & $\mathbf{2 0 1 7}$ г. & $\mathbf{2 0 1 8}$ г. & средняя \\
\hline СибНИИК-30 & 118,32 & 64,86 & 91,59 & 19,19 & 19,16 & 19,17 \\
\hline $\begin{array}{c}\text { Дикорос 1 } \\
(2015)\end{array}$ & 31,45 & 153,68 & 92,57 & 5,56 & 12,29 & 8,92 \\
\hline $\begin{array}{c}\text { Дикорос 2 } \\
(2016)\end{array}$ & - & 93,60 & - & - & 12,02 & - \\
\hline Дикорос 3 & 20,79 & 113,54 & 67,17 & 8,07 & 12,82 & 10,45 \\
\hline
\end{tabular}

и неравномерным (табл. 4). Это необходимо будет учитывать в селекционном процессе и при организации семеноводства.

\section{Выводы}

1. Погодные условия Пермского края, несмотря на их контрастность, вполне пригодны для формирования полноценного травостоя эспарцета песчаного в первый год жизни.

2. При дефиците почвенной влаги, высокой температуре воздуха и летнем сроке посева селекционные сортообразцы при сокращающемся световом дне развиваются по озимому типу; при весеннем

Таблица 4

Динамика созревания семян эспарцета песчаного, \% от общего урожая

\begin{tabular}{|c|c|c|c|}
\hline \multirow{2}{*}{ Образец } & \multicolumn{3}{|c|}{ Даты учета } \\
\cline { 2 - 4 } & $\mathbf{2 5 . 0 7 . 2 0 1 8}$ & $\mathbf{3 1 . 0 7 . 2 0 1 8}$ & $\mathbf{6 . 0 8 . 2 0 1 8}$ \\
\hline СибНИИК-30 & 25,29 & 35,97 & $12,33 / 26,41^{*}$ \\
\hline $\begin{array}{c}\text { Дикорос 1 } \\
2015\end{array}$ & 46,80 & 37,59 & 15,61 \\
\hline $\begin{array}{c}\text { Дикорос 2 } \\
2016\end{array}$ & 30,96 & 40,44 & 28,60 \\
\hline Дикорос 3 & 66,70 & 19,81 & 13,49 \\
\hline
\end{tabular}

Примечание: * - последние семена собраны 10.09.2018г. посеве и благоприятном увлажнении - по яровому типу.

3. При вовлечении в селекционный процесс или для производственных целей семян из дикой флоры необходимо учитывать, что независимо от погодных условий и срока посева дикорастущие формы развиваются по озимому типу.

4. Независимо от погодных условий эспарцет песчаный в первый год пользования формирует полноценный укос зеленой массы и гарантированно дает семена.

5. Нестабильность перезимовки, величины урожая корма и семян по годам и изучаемым образцам можно объяснить тем, что в Пермском крае нет районированного сорта, не ведется сортоиспытание этой культуры. Включенные в коллекцию сортообразцы получены из различных регионов, отличных по природноклиматическим условиям от Пермского края. Поэтому очевидна необходимость организации селекционной работы по эспарцету песчаному в местных условиях с обязательным привлечением генетического материала из местной дикой флоры.

Библиографический список

1. Гибадуллина Ф.С., Тагиров М.Ш., Шакиров Ш.К., Шайтанов О.Л. Стратегия развития кормопроизводства и кормоприготовления в республике Татарстан // Многофункциональное адаптивное кормопроизводство. - М., 2013. - С. 122-129.

2. Доспехов Б.А. Методика полевого опыта. - М.: Агропром, 1985. - 351 с.

3. Дмитриев В.И. Повышение эффективности полевого кормопроизводства в Западной Сибири на основе использования агрофитоценозов многолетних и однолетних кормовых культур // Многофункциональное адаптивное кормопроизводство. - М., 2013. - С. 284-288.

4. Зинина Н.П. Изучение коллекции кормовых культур в Архангельской области // Кормопроизводство. - 2015. - № 12. - С. 45-48.

5. Козлов А.С., Мошкина С.В. Роль оптимизации кормовой базы, технологий приготовления и скармливания кормов в молочном скотоводстве // Актуальные проблемы заготовки, хранения и рационального использования кормов. - М., 2009. - С. 115-118. 
6. Генофонд кормовых растений: методы формирования, хранения, изучения и использования для приоритетных задач селекции // Козлова Н.Н. [и др.] Адаптивное кормопроизводство: проблемы и решения. - М.: ФГНУ «Росинформагротех». 2002. - С. 356-364.

7. Косолапов В.M. Перспективы развития кормопроизводства в России // Кормопроизводство. 2008. - № 8. - C. 2-10.

8. Люшинский В.В., Прижуков Ф.Б. Эспарцет / Семеноводство многолетних трав. - М.: Колос, 1973. - С. 87-100.

9. Методические указания по изучению коллекции многолетних кормовых трав. - Л.: Изд-во ВИР, 1973. - С. 37.

10. Методика опытов на сенокосах и пастбищах. - М.: ВНИИК им. В.Р. Вильямса, 1973. - 229 с.

11. Писковацкая Р.Г., Макаева А.М., Толмачева Е.В. Основные направления селекции клевера ползучего // Кормопроизводство. - 2015. - № 12. - С. 35-37.

12. Савченко И.В. Проблемы кормопроизводства и пути их решения в срединном регионе Нечерноземной зоны России // Материалы науч.-практ. конф. «Проблемы и перспективы развития отрасли кормопроизводства в Северо-Восточном регионе Европейской части России»: - Кострома, 2006. - C. 9-16.

13. Тореханов A.A. Генофонд кормовых растений - важнейший элемент сохранения биоразнообразия Казахстана // Кормопроизводство. - 2006. - № 1. - С. 24-26.

14. Шпаков А.С., Воловик В.T. Структура посевных площадей - основа совершенствования полевого кормопроизводства // Ваш сельский консультант. - 2010. - № 2. - С. 29-31.

\title{
THE SELECTION AND THE EVALUATION OF Onobrichis arenaria (Kit) GENETIC MATERIAL IN A COLLECTION NURSERY
}

\author{
V.A. Voloshin \\ Perm Scientific Research Institute of Agriculture
}

The results of studies of sandy sainfoin Onobrichis arenaria (Kit) DC, 1825 of the first year of life and the first year of use obtained in two consistent foundations are presented. The objects of the research included SibNIIK-30, Petushok, Peschanyj 22 cultivars and some samples from the natural flora: S-1, S-2, S-3. Drill sowing method was used for the cultivars, broad drill sowing - for the wildings, due to seed shortage. Sowing rate for cultivars was 400 , for wild plants -200 fertile seeds per $1 \mathrm{~m}^{2}$. The data on seed density, field germination, over-wintering, green mass and seed yields are presented. During summer sowing, within the conditions of soil moisture deficiency in 2016 the studied cultivars were developing according to the winter type, forming in autumn rosettes from 5 or more shortened shoots. During spring sowing and the favorable soil moisture in 2017 the height of young plants reached $76-96 \mathrm{~cm}$, separate flowering shoots were observed, i.e. the development proceeded according to the spring type. The wildings, regardless of the weather conditions and sowing time, were developing according to the winter type, forming 3,3-4,4 and 4,0-5,0 shortened shoots per plant in 2016 and 2017 respectively. In the first foundation, the plants SibNIIK-30 cultivar wintered well, all the rest cultivars and samples had only 50-60\% survived plants. In the second foundation the wildings wintered well, more than $50 \%$ of plants died among the cultivars. On average, during these two foundations green matter total yield of the first year of use varied from 1,28 to $3,46 \mathrm{~kg} / \mathrm{m}^{2}$. The seed yield varied from 59,16 to $-92,57 \mathrm{~g} / \mathrm{m}^{2}$.

Keywords: sandy sainfoin Onobrichis arenaria, cultivars, wildings samples, green matter yield, seed yield.

\section{Сведения об авторе}

Волошин Владимир Алексеевич, доктор сельскохозяйственных наук, главный научный сотрудник лаборатории кормопроизводства, животноводства и ветеринарной медицины, Пермский научноисследовательский институт сельского хозяйства - филиал Пермского федерального исследовательского центра УрО РАН (Пермский НИИСХ), 614532, Пермский край, Пермский район, с. Лобаново, ул. Культуры, 12; e-mail: pniish@rambler.ru 